\title{
Flexible Deixis: A Way to Cognitive Flexibility - The Influence of Perception of Centrifugal Force of Deixis on Transferability of Learning
}

\author{
Razieh Rabbani Yekta \\ Department of Foreign Languages, University of Isfahan, Hizar Jarib Street, Isfahan, Iran \\ Email: Basttan11@yahoo.com \\ Zohreh Kassaian \\ University of Isfahan, Iran \\ Email: zkassaian@yahoo.com
}

\begin{abstract}
In this article, deictic expressions are approached with a view to introduce a way for the promotion of cognitive flexibility of foreign language learners, proposing that such expressions can enhance the authenticity of language tasks whereby learners can see the realities from the eyes of different selves, and represent these realities in their proper multiplicity. More specifically the study investigated how far perception of EFL learners of Deictic Shift during the process of literary comprehension, correlates with the measure of cognitive flexibility, which is, in turn, the function of transfer of learning to limited, near and far situations or tasks. Then, authors, having considered Petraglia's definition of authentic learning as transferability, proposed that narrative activities with the focus on deixis can provide a ground for designing authentic learning task and environment which can weave the cognitive flexibility of language learners in developing multiple representations, multiple selves, and multiple realities.
\end{abstract}

Index Terms - authenticity, cognitive flexibility theory, deictic shift theory, transfer of learning

\section{INTRODUCTION}

The progressive reforms of twentieth century education have at their heart the recognition of the importance of a sense of reality or authenticity_ culminating in the current educational movement called constructivism, in which each student constructs his or her own knowledge of the world. In Psychology also, such tendencies toward reality have led to the current concern for situated cognition, an approach that again emphasizes the individual's perception of and responsiveness to the immediate ambient world and motivating activities that seem personally real.

But constructivism and situated cognition have a hidden kicker. If realities are constructed through individual activities and perceptions, then realities are multiple and we can not rely on any reality we offer students to be authentic prior to their engagement with it.

A constructivist theory of instruction and learning, Cognitive Flexibility Theory (Spiro et al, 1988) provides remedy to these problems. Cognitive Flexibility Theory offers an extension to the idea of the way we process new information, suggesting that we do not simply retrieve packets of old knowledge but we assemble them to form new realities which best relate to the learning of new material. It advocates avoiding oversimplification instruction, providing multiple representations of content, emphasizing case-based instruction, context dependent knowledge, knowledge construction and not transmission, and introducing complexity at an early stage. A central metaphor associated with Cognitive Flexibility Theory is the criss-crossing of a conceptual landscape revisited from different directions in order to master the complexity and fullness of a domain, a metaphor originated from Ludwig Wittgenstein's philosophical work expounded in Philosophical Investigations (Wittgenstein, 1985). By criss-crossing the same area from different perspectives, a web-like form of highly connected knowledge structure is created, allowing for flexibility in the application of knowledge to novel situations (transfer of learning). A shift from single to multiple representations, from rote learning to knowledge assembly, from schema retrieval to situation-specific knowledge assembly should be realised: "information that will need to be used in a lot of different ways needs to be taught in lots of different ways" (Spiro, et al, 1987, p.188).

The method most appropriate to translate the principles of Cognitive Flexibility Theory is hypertext as hypertexts provide non-linear links that allow for multiple dimensions of knowledge representation and multiple interconnections across knowledge components. But, in this article, authors propose that narrative activities with the focus on deixis can also provide a context or ground for designing authentic learning task and environment which can weave the cognitive 
flexibility of language learners in developing multiple representations, multiple selves, and multiple realities.

To this end, the study investigated the effects of the perception of Deictic shift on the measure of cognitive flexibility, which is, in turn, the function of transfer of learning to limited, near and far situations or tasks, as measured by achievement, performance and proficiency tests respectively.

Following research questions are addressed in the current study:

1. Is there any relationship between students' perception of deictic shift, and transfer ability of learners of literary comprehension as measured by limited, near and far transfer tests?

2. If yes, perception of which types of Deictic Center shift can best be potential predictors of EFL students' ability in limited, near, and far transfer of literary comprehension?

A present article is the report of a correlational study, conducted to answer the above question. In doing this research, authenticity, narrative-centered learning, deictic shift theory, and transfer of learning, have been considered which are presented briefly in the next section.

\section{THEORETICAL BACKGROUND OF THE STUDY}

\section{A. Narrative as an Authentic Activity}

Petraglia in a thorough review of the concept of authenticity as a goal — what he calls a desideratum - in education, wants to show that the "Western educational tradition has culminated in the contemporary and widespread view that school learning should rightfully, and nontrivially, correspond to the world outside of school"; moreover, this objective is "the result of a confluence of socially and culturally informed choices." Authenticity, he argues, is "not an intrinsic property possessed by an object but rather a judgment, a decision made on the part of the learner constrained by the sociocultural matrix within which he or she operates." That's why Petraglia insists that teachers must argue for the authenticity of their subject matter and their pedagogy. He also investigates teachers' attempts to "pre-authenticate" by designing syllabi, selecting course readings, creating tasks, problems, or contexts that individual students will likely judge to be meaningfully connected to their conceptions of reality. Petraglia cites three conditions of authenticity: the learner feels "ownership" over or "responsibility" for learning; the task must be "project-based," with the parts contributing to a clear "bigger picture"; and the work must encourage the learner to "generate multiple perspectives." "it is one thing," he reminds his readers, "to understand learning in everyday situations and entirely another thing to capture the dynamics of that learning and then set them in motion on cue."---___For Petraglia, therefore, narrative activities can be considered authentic. Narrative-centered learning environments offer significant potential for supporting guided exploratory learning. By taking advantage of the inherent structure of narrative, narrative-centered environments provide students with engaging worlds in which they actively participate in motivating story-based problem solving activities. Narrative could play an important role in discovery learning (Bruner, J. 1961), an approach to learning that emphasizes students' active exploration of a subject matter. In stark contrast to didactic pedagogies that emphasize students' memorization of facts from lectures and reading, discovery learning encourages students to learn by trial-and-error: they pose questions and answer them by conducting experiments, manipulating artifacts in physical or simulated environments, analyzing information, and systematically generating and testing their hypotheses (White, B. and Fredricksen, J. 1998). It is widely believed that discovery learning offers much promise because students actively participate in problem-solving activities (National Research Counsel, 1996). However, it has been demonstrated that "pure" discovery learning in which students receive no guidance in the form of coaching and hints from a teacher or learning environment is ineffective (Mayer, R., 2004). ___ For example, one of the central activities in comprehension of literary texts such as narratives is specifying the orientation of the narrative discourse consisting of time setting, spatial setting, as well as characters, which are essential to the literal comprehension of a discourse (Hong-mei, et al., 2009). Generally speaking, the expressions of time, locations and the characters are realized by the use of deictic words and expressions. Consequently, the understanding of these deictic expressions is crucial to the identification of the orientation of the discourse, thus completing the literal comprehension of narratives. For instance, the specification of reference of person deixis like "I", "you", "his", "our", etc. is essential to clarify the characters in the discourse. In addition, in order to specify the location of the events described in the discourse, the reader is supposed to understand such space deixis as "here", "there", "at the place" and so on. Another activity is outlining the storyline of the narrative discourse. In this activity, in addition to person deixis, the understanding of time deixis is equally important to the literal comprehension of a discourse since the outlining of the storyline of a narrative relies largely on the specification of time deixis, the understanding of which will also be impossible without our co-text knowledge.

\section{B. Deictic Shift Theory}

Of course, deixis in the story world itself is not structured by either the author's or the reader's actual world. How, then, does the reader comprehend, not just the deictic references in fictional narratives, but the fictional narratives themselves, which, like all human communication, depend for their very coherence on deixis and reference? According to deictic shift theory, the reader creates a mental model of the story world and then projects, or shifts, her deictic center into that model (Bennett, 2005). That is, in the process of reading, the reader responds to the textual cues provided by the author (who has likewise taken up one or more perspectives within the text in the process of creating it) to construct a deictic coordinate system in the world of the narrative. The reader then continues to reconstruct and reorient the 
deictic center, as cued by the text, during the course of the narrative. With respect to a particular narrated event, specific morphological, lexical, and syntactic elements of the text direct the reader to an active spatiotemporal location within the mental model when and where the reader witnesses the event (Segal 1990, 1995). One of the particular strengths of deictic shift theory is its identification and classification of these textual elements and their specific effects on the deictic center.

The deictic center of the text - the "window" from which the reader witnesses fictional events or, more generally, the perspective from which the reader experiences the elements of the story world - contains the components of the WHO (the narrative's participant structure), the WHERE (its spatial structure), the WHEN (its temporal structure), and the WHAT (its object structure; Zubin and Hewitt 1995).

\section{Cognitive Flexibility and Transfer of Learning}

As it was mentioned in the introduction, cognitive flexibility allows for flexibility in the application of knowledge to novel situations. Extending this to classroom learning in general, and foreign language learning, in particular, then, one can expect three types of learning: limited transfer, near transfer, and far transfer learning (Clifford, 2008).

- With limited transfer learning, students...

- Memorize and practice specific responses.

- Focus is on the content of a specific course, textbook, or curriculum.

- Learn only what is taught.

- With near transfer learning, students...

- Go beyond rote responses to rehearsed and semi-rehearsed responses.

- Focus on a predetermined set of tasks or settings.

- Apply what they learn within a range of familiar, predictable settings.

- With learning for far transfer, students...

- Develop the ability to transfer what is learned from one context to another.

- Acquire the knowledge and skills needed to respond spontaneously to new, unknown, or unpredictable situations.

- Learn how to continue learning and to become independent learners.

Aligned with these types of learning, there are three types of testing: achievement, performance and proficiency test.

- Achievement tests measure:

- Practiced, memorized responses.

- What was taught.

- The content of a specific textbook or curriculum.

- Performance tests measure:

- Rehearsed and semi-rehearsed responses.

- Ability to respond in constrained, familiar, and predictable settings.

- Whether learning transfers to similar situations.

- Proficiency tests measure:

- Whether skills are transferable to new tasks.

- Spontaneous, unrehearsed abilities.

- General ability to accomplish tasks across a wide variety of real-world settings.

In the present study, authors tried to test the predictability of limited, near and far transfer ability of learners with perception of deictic shift. To this end, the researchers run a series of multiple regression analyses with Deictic Shift dimensions as possible predictors and the dependent variables (achievement, performance and proficiency test scores) as the criterial variables. They were simultaneously entered by selecting the stepwise entry mode in the analysis process.

\section{MEthodology}

\section{A. Participants}

The sample of the study involved a cohort of 60 EFL students at the Faculty of Foreign Languages, University of Isfahan, who registered for the course Simple English Prose. They were both male and female between the ages of 19 and 22. A TOFEL test was used with students as a result of which final group of students included those who scored 550 and above on the TOEFL test. In this study, we presented participants with true-false statements about a narrative that they were in the process of reading. This was done by presenting the text a few sentences at a time and then presenting the true-false statements after each set of sentences. Three versions of the text were constructed in order to compare the movement of the Deictic Centers of the text, as evident in answers to who, where- and when-questions, as a function of the linguistic devices used in the different versions. Score from true false tests, then entered into correlation with participants' scores on an /a 1) achievement test, 2) performance test, and 3) proficiency test respectively which are aligned with limited, near, and far transfer ability.

\section{B. Method}

Three versions of the first chapter of The Pearl were composed. Twenty-five sentences differed across the versions in 
one of two ways:

1. When a movement of characters in the story from one location to another was described by Steinbeck using the verbs 'came' or 'went', we substituted 'came' for 'went' and 'went' for 'came' in half of the instances selected. The changes were distributed equally over the three versions.

2. When, in the original text, the location of an entity or an event was either deictically identified, identified by the use of a preposed adverbial, or identified by the use of an adverbial elsewhere in the sentence, we sometimes inserted, moved, or deleted adverbials. Each instance selected occurred without an adverbial or with the adverbial in initial or non-initial position. These three possibilities occurred in the three different versions of the text.

In addition to these modifications, several sentences designed to simulate background description were added to the text. These sentences introduced animals to the narrative, with no explicit locatives, in order to see whether the Deictic Center devices under investigation would be used by readers to inferentially determine the animals' locations.

The chapter was broken into 30 units of from 2 to 17 sentences each. There was no attempt to control sentence length or unit length. Subjects were asked to read a unit and then respond to 2 to 6 true-false statements about it. For each version, there were a total of 115 statements. Each statement was to be responded to with a number from 1 (= definitely false) to 6 (= definitely true). Subjects were presented a booklet, each page of which contained one unit of the narrative and the statements associated with that unit. After responding to the statements following one unit, they were asked to turn the page and do the same thing with the next unit. At no time were they to read ahead or to re-read a unit on a previous page.

\section{RESULTS AND DisCUSSION}

A. Predicting limited, near, far transfer ability with perception of Deictic Shift of EFL students

Proficiency test score of students was predicted with three dimensions of their comprehension score. $\{\mathrm{F}(3,159)=$ $15.95, \mathrm{P}<.001\}$, which respectively accounted for $12 \%, 17 \%$, and $23 \%$, respectively, of the total variance in students' achievement score. This indicate that only those EFL students who exhibit higher comprehension score in all three types of deictic shift are able, more likely than their peers, to transfer their comprehension ability to completely new narrative activities.

The performance test score was predicted with the "WHO" and the "WHERE" dimensions of literary comprehension. $\{\mathrm{F}(2,160)=31.05, \mathrm{P}<.001\}$.

Students' achievement was predicted with three comprehension dimensions $:\{\mathrm{F}(3,138)=12.41, \mathrm{P}<.001\}$. These dimensions respectively account for $19 \%, 16 \%$, and $13 \%$ students' language achievement. This denotes that students who have better perception of all three types of deictic shift can act better on test tasks which are in complete alignment with classroom tasks.

\section{CONCLUSION}

The proficiency score was found to be significantly correlated with the literary comprehension of deictic shift in the multiple regression analysis. This fact about the predictive value of literary comprehension of function of different types of deixis in narratives indicates the importance that such elements have in enhancing the depth of the learning to the extent that enable the students to transfer what they have learnt to the remote situations or tasks that are of no familiarity to them. And all of these side effects are due to the flexible nature of deixis which in turn renders the learners' cognitive processes a kind of flexibility required for the engagement in the multiplicity of realities outside.

\section{REFERENCES}

[1] Bennett, A., (2005). Expanding deictic shift theory: person deixis in Chuck Palahniuk's FIGHT CLUB. An Unpublished thesis submitted for the master's degree in the University of Kentucky, Lexington.

[2] Bruner, J. (1961). The act of discovery. Harvard Educational Review, 31:21-32.

[3] Bruner, J. (1990). Acts of Meaning. Harvard University Press, Cambridge, MA.

[4] Clifford, R., (2008). Accelerated language and culture learning: Shortcut methods vs. dead-End methods. A Workshop Presented to Alexandria, VA on Language Learning, an Extremely Complex Task.

[5] Hong-mei, X., Jing-yuan, Z., \& Yong-wei, W., (2009). The roles of context in the interpretation of the English narrative discourse. US-China Foreign Language Journal, V. 7, No.7.

[6] Mayer, R. (2004). Should there be a three-strikes rule against pure discovery learning? American Psychologist, 59(1):14-19.

[7] National Research Counsel. (1996). National Science Education Standards. National Academy Press, Washington DC.

[8] Petraglia, J. (1998). Reality by Design: The Rhetoric and Technology of Authenticity in Education, Manwah, NJ: Lawrence Erlbaum.

[9] Segal, Erwin M. (1990). Fictional narrative comprehension: Structuring the deictic center. Proceedings of the 12th Annual Conference of the Cognitive Science Society, 526-533. Hillsdale, NJ: Lawrence Erlbaum.

[10] Spiro, R. J., Vispoel, W. L., Schmitz, J. G., Samarapungavan, A. \& Boerger, A. E. (1987). Knowledge acquisition for application: cognitive flexibility and transfer in complex content domains. Technical Report No. 409, Urbana-Champaign, IL: University of Illinois, Centre for the Study of Reading, 188.

[11] Spiro, R. J., Coulson, R. L., Feltovitch, P. J., \& Anderson, J. K. (1988). Cognitive flexibility theory: advanced knowledge acquisition in ill-structured domains. Patel, V. (ed.) Tenth Annual Conference of the Cognitive Science Society. Hillsdale, NJ: 
Lawrence Erlbaum.

[12] White, B. and Fredricksen, J. (1998). Inquiry, modeling, and metacognition: making science accessible to all students. Cognition and Instruction, 16:3-118.

[13] Wittgenstein, L. (1985). Philosophical Investigations. London, Basil Blackwell \& Mott, [Lourenço, M. S. (trad.) (1987) Tratado Lógicl-Filosófico *Investigações Filosóficas, Lisboa: Fundação Calouste Gulbenkian].

[14] Zubin, David A., and Lynne E. Hewitt. (1995). The deictic center: A theory of deixis in narrative. In Duchan et al. 1995, 129-155.

Razieh Rabbani Yekta earned her M.A. in TEFL from Isfahan University and is now a PhD candidate studying there. Her research area includes second language acquisition, psycholinguistic, materials development and course design and has published papers in these areas. She has been a teacher of translation and ELT courses in Isfahan University and a number of other foreign language institutes and the reviewer of Asia TEFL Journal.

Zohreh Kassaian, Ph.D. in TEFL, is currently teaching and researching various topics at graduate and undergraduate levels at the University of Isfahan. Her areas of interests are psycholinguistics, theories of learning, translation and language teaching and has published and presented papers widely in these areas.

Dr. Kassaian has written a book series used in Language Laboratory for EFL students. She is, at the moment, the president of Sobh Sadegh University. 